\title{
20. An Analysis of the Field of Diurnal Variations of Terrestrial Magnetism of Different Types.
}

\section{(A Supplementary Treatise)}

\author{
By Mankiti Hasegawa and Masazirô ÔTA. \\ Geophysical Institute, Kyoto Imperial University. \\ (Comm. by A. Tanakadate, M.I.A., March 12, 1937.)
}

In a former article (1), ${ }^{1)}$ we calculated the potential of the magnetic field of diurnal variations from the $X$ and $Y$ components separately. In this paper, we adopt, for the expansion in a series of spherical harmonics, the values taken from the potential charts inserted in another article $\left.(2),{ }^{2}\right)$ in which the values of the potential derived from the $X$ component are corrected so as to accord, as much as possible, with those derived from the $Y$ component. The results of the calculation are now briefly described herewith. ${ }^{3)}$

It is to be noticed that the coefficients of the first few terms in the expansion of the magnetic potential obtained by the method of least squares come out too large, especially when the applied range of latitude is limited. In the former calculation the terms in $n=1-4$ for $m=1$ were calculated for the range $\pm 45^{\circ}$ of latitude. The coefficients of $P_{1}^{1}$ were two or three times as large as the new results determined by the usual method of integration, for the known values of $X$ from $90^{\circ} \mathrm{N}$ to $90^{\circ} \mathrm{S}$. We described in another paper $^{4)}$ in these proceedings the difficulty of determining the $Z$ component over the earth. Consequently, for the $Z$ component, we had to employ the method of least squares within the range of $\pm 60^{\circ}$ of latitude. Examining the coefficients in $n=1-6$ for $m=1, n=2-5$ for $m=2$ and $n=3-4$ for $m=3$, the effects of the remaining higher terms are found to be negligible as to the final results. In the table the external and internal coefficients $\left(E_{n}^{m}\right.$ and $\left.I_{n}^{m}\right)$ of the main terms are given and the total effect of all the terms can be seen in the charts of the equivalent electric currents.

Comparing the figures in this table with those in the previous paper (1), a good deal of improvement can be seen with respect to both the representation of the original magnetic field and the expression of the characteristics of the types of diurnal variations.

The most important conclusion is that in the charts of IX, 23, the principal centre of circulation of the external electric current lies nearly at the latitude $30^{\circ} \mathrm{N}$, while that of the internal current lies at about $45^{\circ} \mathrm{N}$. This result is consistent with our previous suggestion concerning the twin structure of equipotentials in the example in the same

1) Proc. 12 (1936), $221 . \quad 2)$ Proc. 12 (1936), 225.

3) In this calculation we used the "normierte Funktionen" after Ad. Schmidt (see Handb. d. Exp. Phys. XXV. T. 1, p. 191). In order to compare the coefficients in this paper with those in the former (1), they must be multiplied with the factor $\varepsilon_{n}^{m}=\sqrt{2(n-m) ! /(n+m) !}$.

4) Proc. 13 (1937), 69. 
paper (2). The main center of potential is due to the internal causes, and what was called the satellite center is of external origin. A similar tendency can be seen in the charts of VI, 23. It is also to be remarked that the external as well as the internal systems of electric current in these cases distinctly differ in the two days of comparision. Hence, there is no doubt that such a twin structure is by no means a sole necessary condition for defining a type of diurnal variations.

\begin{tabular}{|c|c|c|c|c|c|c|c|c|c|c|c|c|c|c|c|c|c|}
\hline \multirow[b]{2}{*}{$m$} & \multirow[b]{2}{*}{$n$} & \multicolumn{4}{|c|}{ VI $21(P)$} & \multicolumn{4}{|c|}{ VI $23(E)$} & \multicolumn{4}{|c|}{ IX $23(E)$} & \multicolumn{4}{|c|}{ IX $24(P)$} \\
\hline & & $E_{n}^{m}$ & $a_{e n}^{m}$ & $I_{n}^{m}$ & $a_{i n}^{m}$ & $E_{n}^{m}$ & $a_{e n}^{m}$ & $I_{n}^{m}$ & $a_{i n}^{m}$ & $E_{n}^{m}$ & $a_{e n}^{m}$ & $I_{n}^{m}$ & $a_{i n}^{m}$ & $E_{n}^{m}$ & $a_{e n}^{m}$ & $I_{n}^{m}$ & $a_{i n}^{m}$ \\
\hline 1 & 1 & 3.1 & $153^{\circ}$ & 1.5 & $193^{\circ}$ & 4 & & 6 & & 6 & & & $2^{\circ}$ & 5 & $7^{\circ}$ & .4 & $236^{\circ}$ \\
\hline 1 & 2 & 4 & 129 & 2. & 131 & 5.4 & 121 & 2.2 & 124 & 4.7 & 141 & 3.7 & & 3.1 & 137 & 0 & 12 \\
\hline 1 & 3 & 0. & 63 & 0. & 88 & & 95 & 0.4 & 97 & 0.3 & 44 & 0.3 & & 1.7 & 294 & & \\
\hline 1 & 4 & 1. & 283 & 0.5 & 344 & 1.5 & 282 & 0.5 & 357 & 2.7 & 277 & 0.7 & 40 & 3.0 & 267 & 9 & 35 \\
\hline & 2 & 0.8 & 0 & 0 . & 15 & 0.6 & 104 & 0.7 & 172 & & 3 & $\because 2$ & & 1 & 23 & & 1 \\
\hline 2 & 3 & 2.6 & 350 & 0. & 18 & 2.7 & 341 & 1.2 & 2 & 2.7 & 320 & 1.3 & 9 & 1.8 & 333 & 2 & 11 \\
\hline 2 & 4 & 0.5 & 307 & 0.3 & 32 & 1.3 & 327 & 0.6 & 331 & & 28 & 0.9 & 2 & & & 2 & 234 \\
\hline & 3 & 1.4 & 241 & 0.5 & 170 & 0.8 & 38 & 1.0 & 69 & 0.4 & 20 & 1.1 & 12 & 1. & 294 & 0.9 & 27 \\
\hline 3 & 4 & 0.7 & 228 & 0.4 & 3 & 1.0 & 267 & 0.6 & 294 & 0.8 & 237 & 1.0 & 276 & 0.6 & 255 & 0.3 & 274 \\
\hline
\end{tabular}

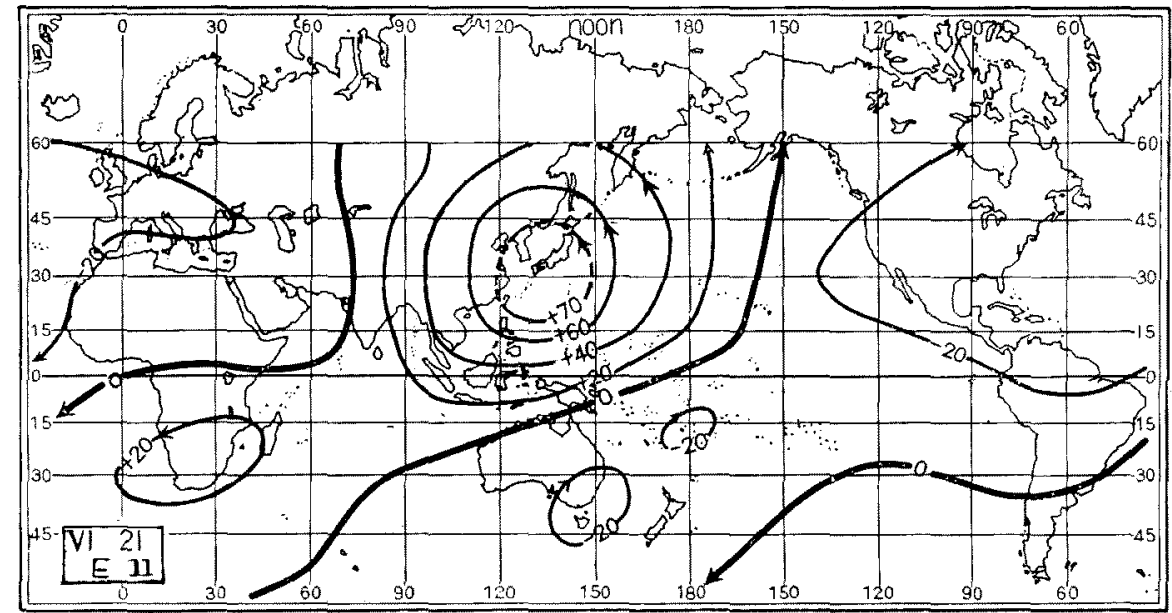

Chart 1. External electric current system at $2^{\text {h }}$ G. M. T. June 21, 1934.

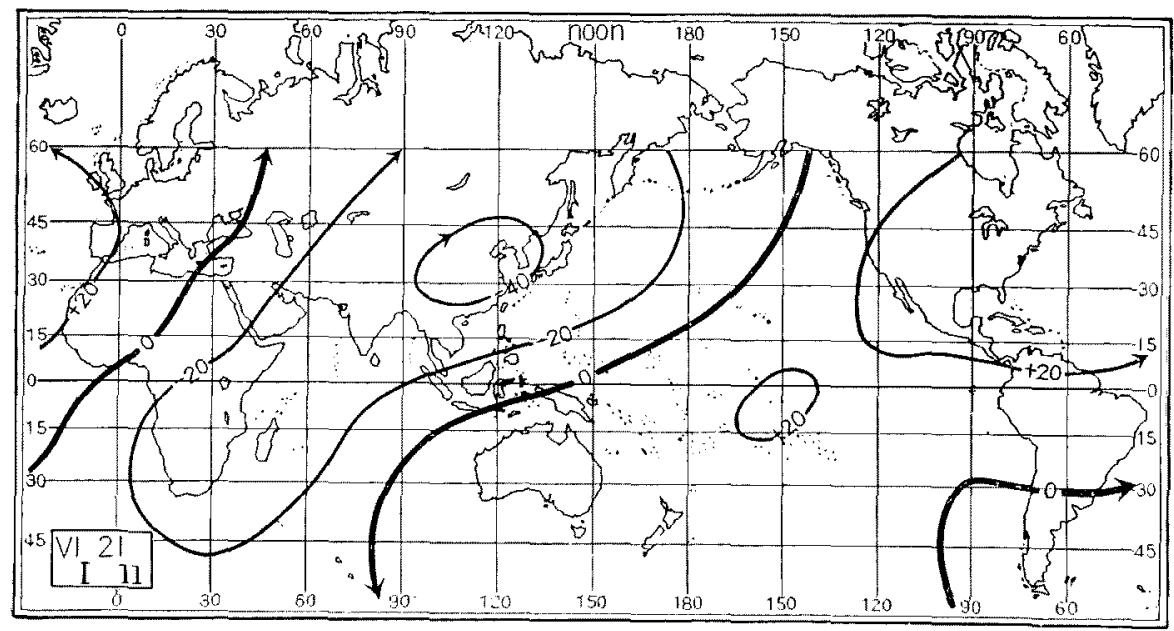

Chart 2. Internal electric current system at $2^{\text {h }}$ G. M. T. June 21, 1934.

Note 1. In the calculation, Greenwich meridian was taken as the origin of longitude.

2. The electric current in these charts is expressed in the unit of $1000 \mathrm{Amp}$. 


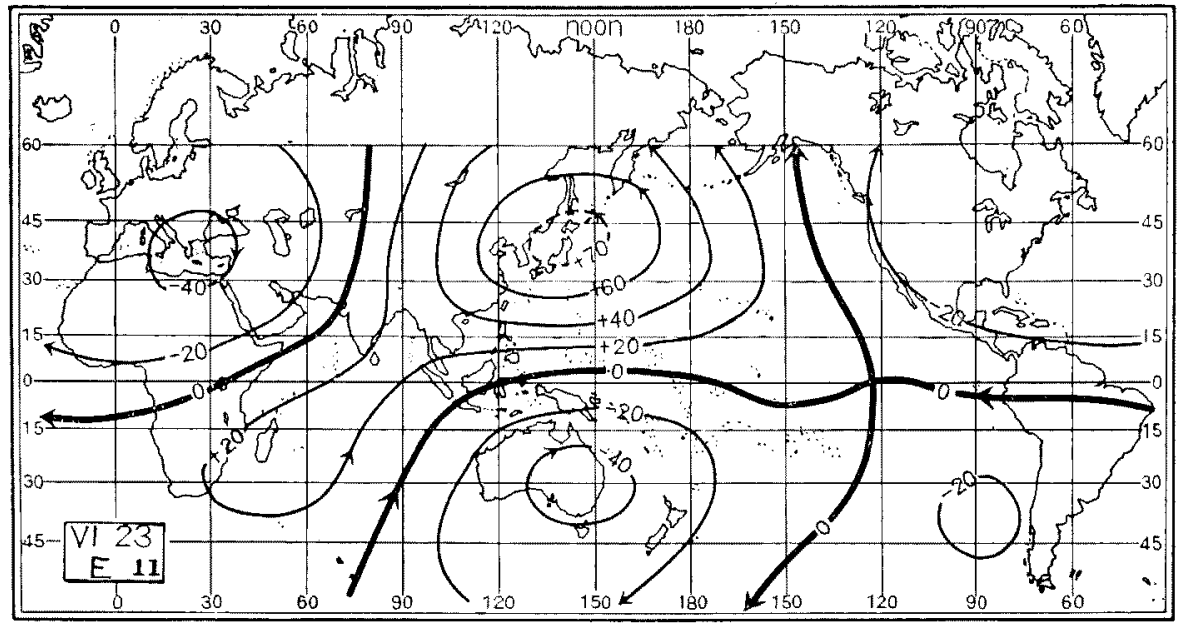

Chart 3. External electric current system at $2^{\text {h }}$ G. M.T. June 23, 1934.

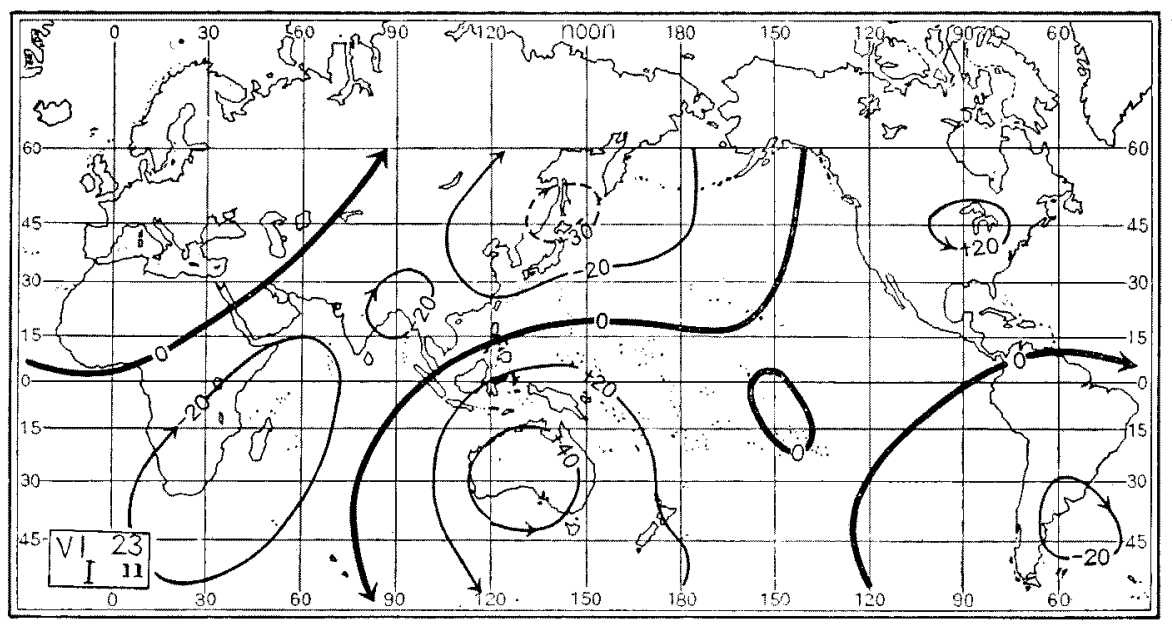

Chart 4. Internal electric current system at $2^{\mathrm{h}}$ G. M. T. June 23, 1934.

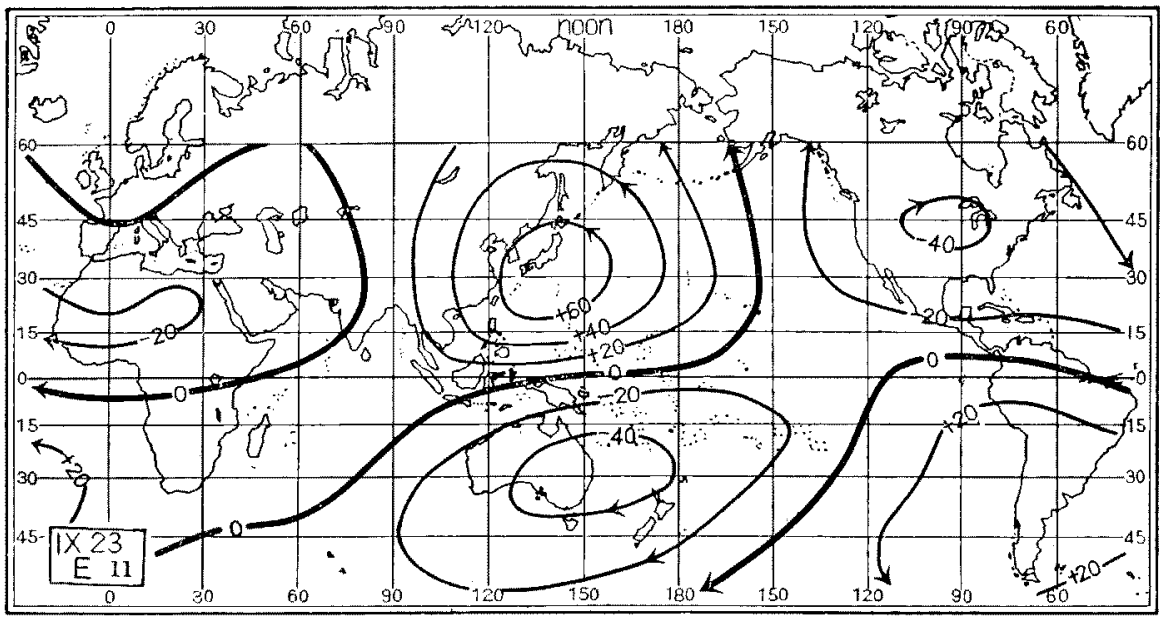

Chart 5. External electric current system at $2^{\text {h }}$ G. M. T. Sept. 23, 1933. 


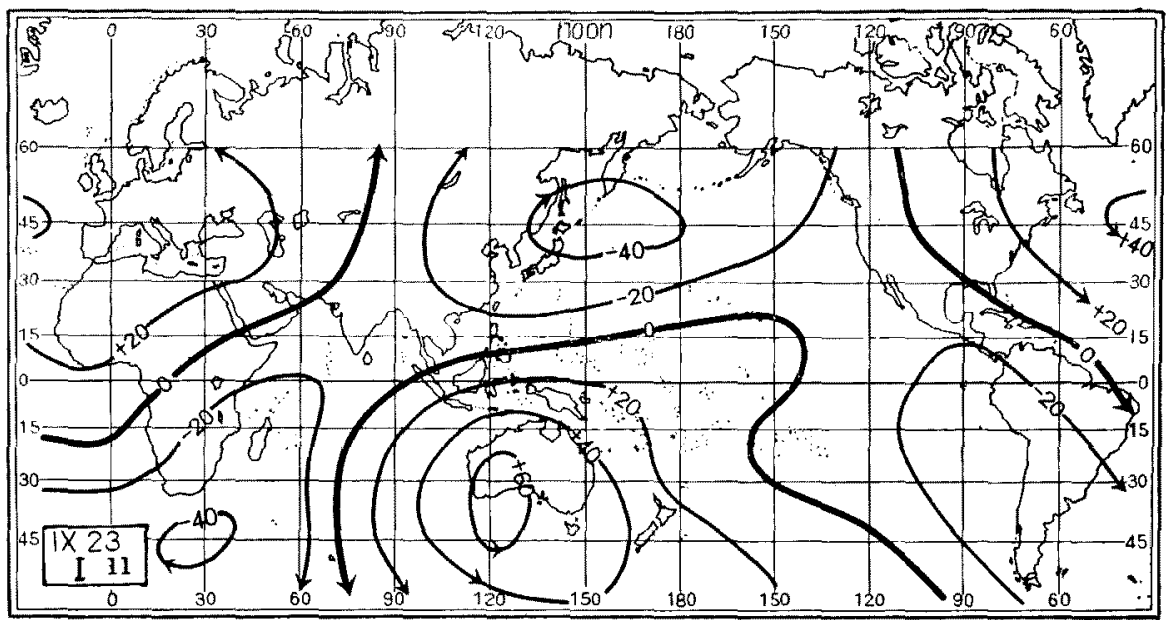

Chart 6. Internal electric current system at $2^{\text {h }}$ G. M.T. Sept. 23, 1933.

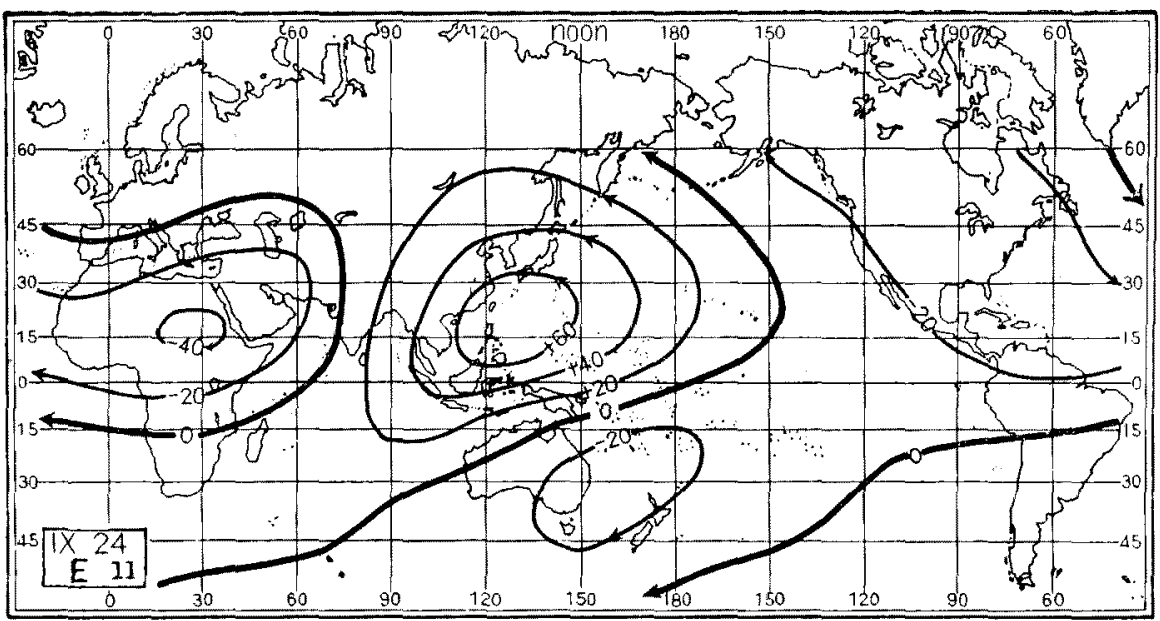

Chart 7. External electric current system at $2^{\text {h }}$ G. M.T. Sept. 24, 1933.

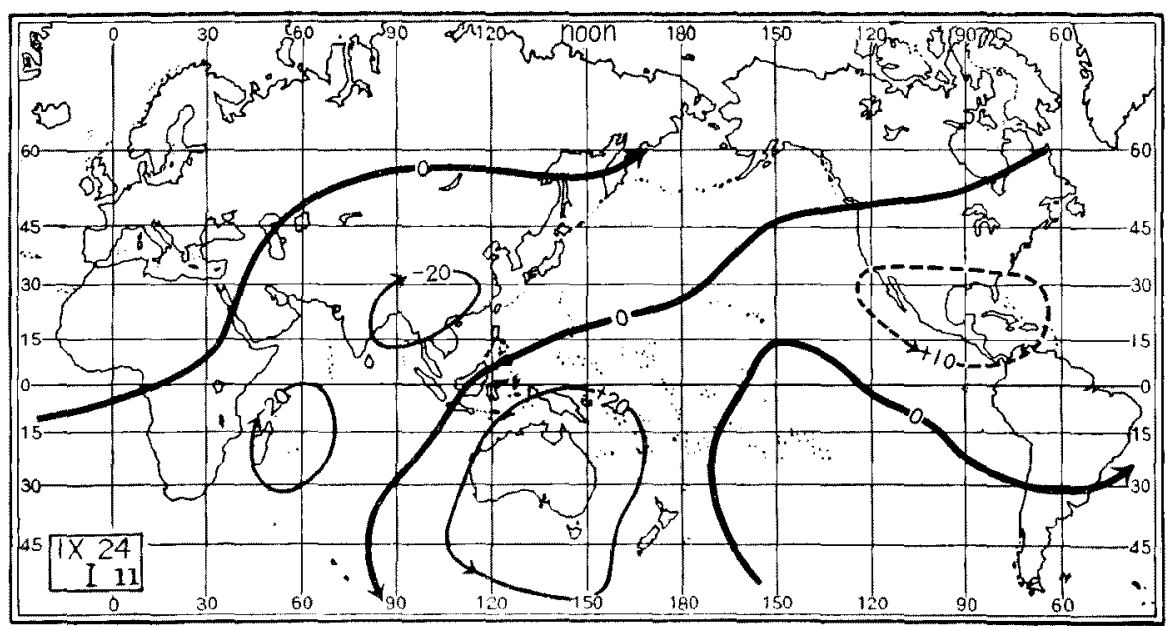

Chart 8. Internal electric current system at $2^{\text {h }}$ G. M.T. Sept. 24, 1933. 